\title{
Evaluation of Circulating Fatty Acid Synthase as a Biomarker in Non-Alcoholic Fatty Liver Disease
}

\author{
Aida Abdeen Mahmoud1, Asmaa N. Mohammad ${ }^{2}$, Mohamed Abdel Wahab Ezat ${ }^{3}$ \\ ${ }^{1}$ Department of Medical Biochemistry, Faculty of Medicine, Sohag University, Sohag, Egypt \\ ${ }^{2}$ Department of Tropical Medicine, Faculty of Medicine, Sohag University, Sohag, Egypt \\ ${ }^{3}$ Department of Internal Medicine, Faculty of Medicine, Sohag University, Sohag, Egypt \\ Email: ^Asmaanaser25@yahoo.co.uk
}

How to cite this paper: Mahmoud, A.A., Mohammad, A.N. and Ezat, M.A.W. (2016) Evaluation of Circulating Fatty Acid Synthase as a Biomarker in Non-Alcoholic Fatty Liver Disease. Open Journal of Gastroenterology, 6, 229-237. http://dx.doi.org/10.4236/ojgas.2016.69028

Received: July 25, 2016

Accepted: August 27, 2016

Published: August 30, 2016

Copyright (C) 2016 by authors and Scientific Research Publishing Inc. This work is licensed under the Creative Commons Attribution International License (CC BY 4.0)

http://creativecommons.org/licenses/by/4.0/

\section{Abstract}

Background: The liver is the corner stone in lipid metabolism, free fatty acid uptake, synthesizing, storing and exporting lipids; non-alcoholic fatty liver disease (NAFLD) develops if there is any interruption or derangements in lipid metabolim. Fatty acid synthase (FAS) is the major enzyme in lipogenesis, and its circulating level is a biomarker of metabolically demanding human diseases. Aim of the Work: To evaluate the level of circulating FAS in NAFLD patients and to correlate it to serum lipid parameters. Materials and Methods: The study included forty NAFLD patients and forty age and sex-matched healthy subjects as controls. Results: FAS levels were significantly higher in NAFLD patients compared to their level in the controls $(\mathrm{P}<0.05)$. Additionally, a positive correlation was found between the levels of FAS and BMI ( $r$ $=0.57$ ), and between FAS levels and triglycerides and low density lipoprotein cholesterol levels in NAFLD patients $(r=0.79 \& 0.53$, respectively). Conclusion: Elevated levels of circulating FAS can be considered as a biomarker of fatty liver disease.

\section{Keywords}

NAFLD, Fatty Acid Synthase, Free Fatty Acids

\section{Introduction}

Non-alcoholic fatty liver disease (NAFLD) may be present as simple steatosis and progress to non-alcoholic steatohepatitis (NASH). This inflammation of the liver tissue is a prerequisite to hepatic fibrosis and cirrhosis. NAFLD represents an important and common cause of liver disease worldwide. It is commonly associated with other medical problems such as obesity, cardiovascular disease, diabetes and metabolic syndrome

[1]. Body fat distribution and visceral fat mass are strongly linked to insulin resistance 
and NAFLD more than the total amount of adipose tissue [2]. Free fatty acids are released from the visceral fat then transported to the liver through the portal circulation and may contribute to hepatic steatosis, production of triglyceride, and very low density lipoproteins (VLDL) and result in elevated $\beta$-oxidation [3].

Fatty-acid synthase (FAS) (EC 2.3.1.85"2.3.1.85) is a key enzyme in lipogenesis. Its main function is to catalyze the synthesis of palmitate from acetyl-CoA and malonyl$\mathrm{CoA}$, in the presence of NADPH [4]. FAS is a multi-enzyme protein, composed of two identical $272 \mathrm{kDa}$ multifunctional polypeptides, in which substrates are handed from one functional domain to the next [5]. FAS catalyzing the final step in FA biosynthesis, is well known to be the major determinant of the generation of hepatic FA by de novo lipogenesis. Altered FAS expression has been correlated with obesity related insulin resistance and hepatic steatosis, functions normally in the liver and is minimally expressed in other tissues [6]. FAS is a key enzyme in de novo lipogenesis [7], and both FAS gene expression and enzymatic activity are primarily regulated by metabolic signals in the liver [8].

Despite being an intracellular protein, it may be released into the extracellular space and may be a biomarker of metabolically demanding human diseases [9]. Increased FAS levels have been detected in serum of patients with different clinical stages of breast cancer [10]. A significant association between circulating levels of FAS and HER2-over expressing metastatic breast cancer patients has been described [11]. A previous study showed that serum levels of FAS in colorectal cancer patients were associated with tumor stage, suggesting that serum FAS detection can be used for distinguishing the patients with metastatic colorectal cancer [12]. High serum levels of FAS have been detected in patients with chronic hepatitis viral infections and circulating FAS concentration correlated with the degree of liver steatosis [13]. In this investigation, we aimed to study FAS in NAFLD and correlate its level to lipid parameters.

\section{Materials and Methods}

\subsection{Study Population}

The study included 40 patients with NAFLD, recruited from the Tropical Medicine and Internal Medicine Departments of Sohag University Hospital and 40 age and sex matched healthy control subjects. Body mass index (BMI) was calculated for all the participants and defined as body weight (in $\mathrm{kg}$ ) divided by height ${ }^{2}$ (in $\mathrm{m}^{2}$ ). Inclusion criteria: any patient diagnosed to have fatty liver. Diagnosis of fatty liver was based on the brightness of the liver on ultrasound as compared with the kidney, vascular blurring of the hepatic vein trunk, deep attenuation in the right hepatic lobe, increase in the fine echoes of hepatic parenchyma with impaired visualization of the intra hepatic vessels and diaphragm. The absence of fatty liver change was defined as a normal echo texture without visible fatty change [14]. The exclusion criteria were any patient with other hepatic disease (viral hepatitis B and C alcohol intake, autoimmune liver diseases, hemochromatosis, liver cirrhosis, etc.) also patients with diabetes mellitus (type 1 or 2), patients with any chronic disease, and history of regular use of steatosis-inducing drugs 
(corticosteroids, valproic acid, tamoxifen, amiodarone).

The study was approved by the Ethical committee of Sohag faculty of Medicine and informed written consents will be obtained from all subjects included in the study.

\subsection{Blood Collection}

Over-night fasting blood samples $(3 \mathrm{ml})$ were collected from the patients and the controls via the venipuncture of an antecubital vein. Samples were centrifuged at $1000 \times \mathrm{g}$ for $20 \mathrm{~min}$., and the serum was separated for the estimation of lipid parameters, blood glucose, liver enzymes and FASN. Routine biochemical tests were performed promptly and the remaining serum was frozen in aliquots and stored at $-20^{\circ} \mathrm{C}$ till assay of FASN .

\subsection{Laboratory Investigation}

Fasting blood sugar (FBG), lipid parameters [total cholesterol (TC), HDL-cholesterol (HDL-C) and triglycerides (TG)] and liver enzymes (ALT and AST) were measured by enzymatic colorimetric methods by Beckman Coulter AU Apparatus. Fatty acid synthase was measured by an ELISA test kit Catalog no., ABIN415272, according to the manufacturer instructions.

\subsection{Statistical Analysis}

Data were expressed as means \pm SD. Differences between groups were tested using the Student's t-test. Pearson correlation test was performed to determine the relationship between the parameters. P-values less than 0.05 were considered significant. All statistical calculations were performed using the computer program SPSS (Statistical Package for the Social Science; SPSS, Chicago, IL, USA) version 16 for Microsoft Windows, USA).

\section{Results}

Obtained results revealed no significant differences between NAFLD patients and controls regarding age or sex distribution, BMI was higher in the patients than in the controls. The levels of TC, TG and LDL-C increased, while HDL-C level decreased significantly in the patients compared to their levels in the controls $(\mathrm{P}<0.05)$. Alanine and aspartatetransaminases (ALT and AST) were significantly higher in NAFLD patients than in controls $(\mathrm{P}<0.05)$. Our results also showed a significant increase in FAS level in NAFLD patients compared to controls $(\mathrm{P}<0.05)$, Table 1 and Figure 1 . A significant correlation was found between FAS level and BMI, TG and LDL-C levels in NAFLD patients, Table 2 and Figures 2-4.

\section{Discussion}

Non-alcoholic fatty liver disease (NAFLD) is highly prevalent worldwide and represents a major public health problem, it ranges from $11 \%$ to $46 \%$. The prevalence can be as high as $98 \%$ in non-diabetic obese individuals. NAFLD has many serious hepatic effects [12]. 
In this investigation, FAS was evaluated in patients with NAFLD and correlated to serum lipid parameters. The results of the study revealed increased FAS levels in NAFLD patients when compared to controls, additionally, a positive correlation was found between FAS level and BMI, serum triglyceride and LDL-C levels. Our results were in accordance with the results obtained in other studies [6] [12] [13].

FAS is the determinant of the increases hepatic capacity to synthesize fatty acids by de novo lipogenesis [7]. In NAFLD Patients FAS was found to be Over-expressed, this is mostly due to increased mitochondrial oxidation of fatty acids [6]. Presence of FAS

Table 1. Clinical and laboratory characteristics of the participants.

\begin{tabular}{ccc}
\hline Parameter & Controls $(\mathbf{n}=40)$ & Patients $(\mathbf{n}=40)$ \\
\hline Sex (male/female) & $18 / 22$ & $16 / 24$ \\
Age (years) & $50 \pm 2.5$ & $51 \pm 3.2$ \\
BMI (kg/m²) & $24.9 \pm 1.9$ & $27 \pm 2.7^{*}$ \\
TC (mg/dL) & $189 \pm 15.7$ & $192 \pm 22.3^{*}$ \\
HDL-C (mg/dL) & $44.3 \pm 3.7$ & $33.6 \pm 7.9^{*}$ \\
TG (mg/dL) & $97 \pm 9.5$ & $145 \pm 30^{*}$ \\
LDL-C (mg/dL) & $118 \pm 10.6$ & $149 \pm 23^{*}$ \\
ALT(U/L) & $30.4 \pm 9.2$ & $55.7 \pm 20.2^{*}$ \\
AST (U/L) & $33.5 \pm 12.6$ & $59.3 \pm 22.5^{*}$ \\
FAS (ng/mL) & $5.2 \pm 0.98$ & $21.5 \pm 8.4^{*}$ \\
\hline
\end{tabular}

${ }^{*} \mathrm{P}$ < 0.05, BMI: Body mass index; TC: Total cholesterol; HDL-C: High density lipoprotein-Cholesterol; TG: Triglycerides; LDL-C: Low density lipoproteins-cholesterol; ALT: alanine amino transferase; AST: Aspartate amino transferase; FAS: Fatty acid synthase.

Table 2. Correlation between FAS and lipid parameters in NAFLD patients.

\begin{tabular}{cccccc}
\hline Parameter & BMI $\left(\mathrm{kg} / \mathrm{m}^{2}\right)$ & TG $(\mathrm{mg} / \mathrm{dL})$ & $\mathrm{TC}(\mathrm{mg} / \mathrm{dL})$ & LDL-C $(\mathrm{mg} / \mathrm{dL})$ & HDL-C $(\mathrm{mg} / \mathrm{dL})$ \\
\hline \multirow{2}{*}{ FAS $(\mathrm{ng} / \mathrm{mL})$} & $\mathrm{r}=0.57^{*}$ & $\mathrm{r}=0.79^{*}$ & $\mathrm{r}=-0.043$ & $\mathrm{r}=0.53^{*}$ & $\mathrm{r}=0.057$ \\
& $\mathrm{P}=0.001$ & $\mathrm{P}=0.001$ & $\mathrm{P}=0.79$ & $\mathrm{P}=0.001$ & $\mathrm{P}=0.73$ \\
\hline
\end{tabular}

“P < 0.05, BMI: Body mass index; TC: Total cholesterol; HDL-C: High density lipoprotein-Cholesterol; TG: Triglycerides; LDL-C: Low density lipoproteins-cholesterol; FAS: Fatty acid synthase.

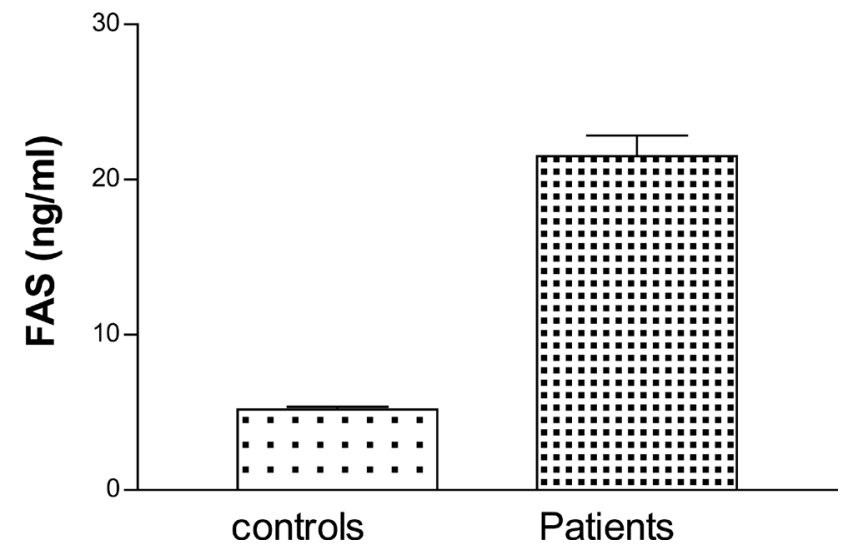

Figure 1. Mean \pm SD of FAS in the controls and NAFAD patients. 


\section{FAS}

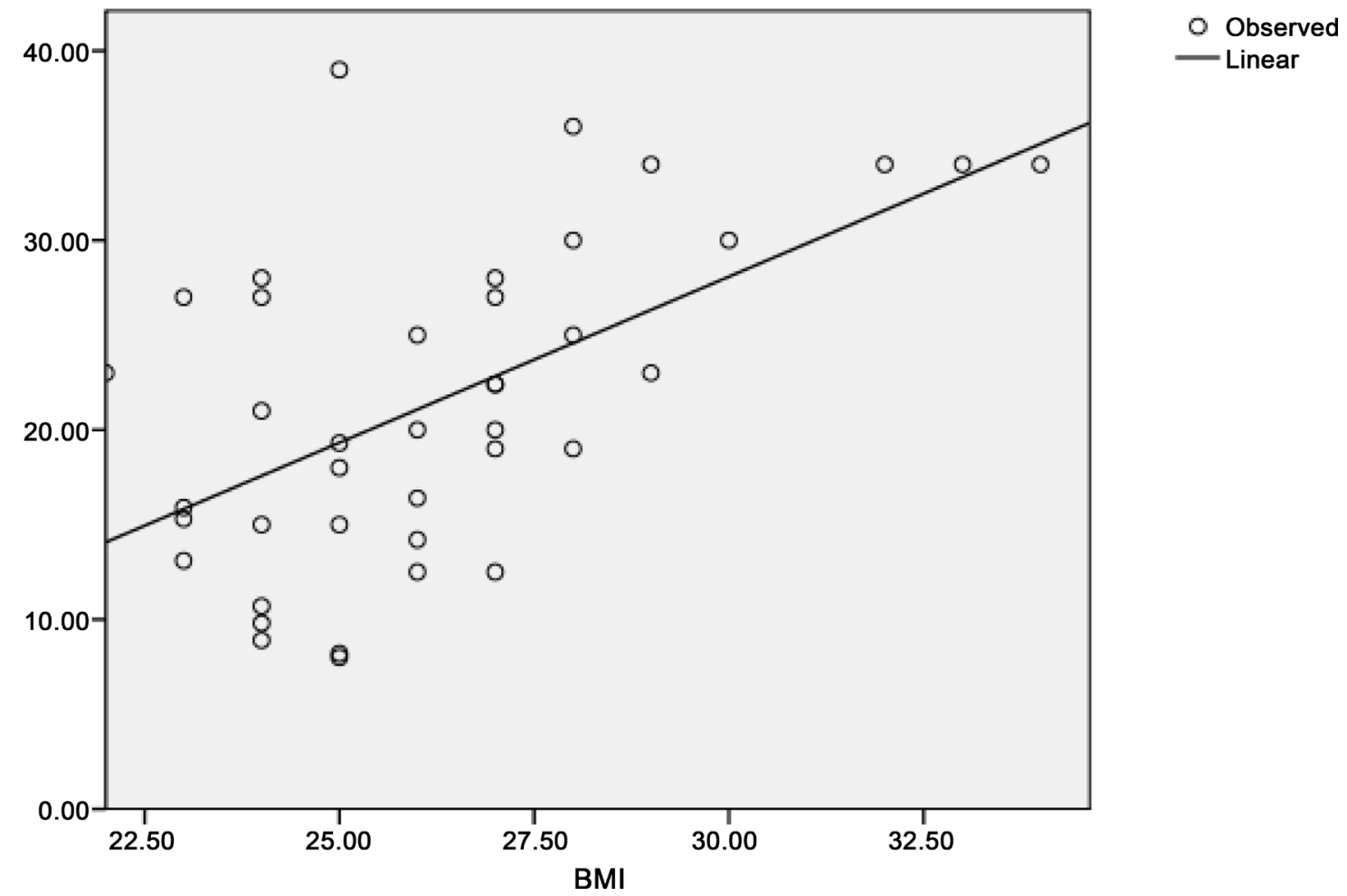

Figure 2. Linear regression analysis showing a positive correlation between BMI and FAS in NAFLD.

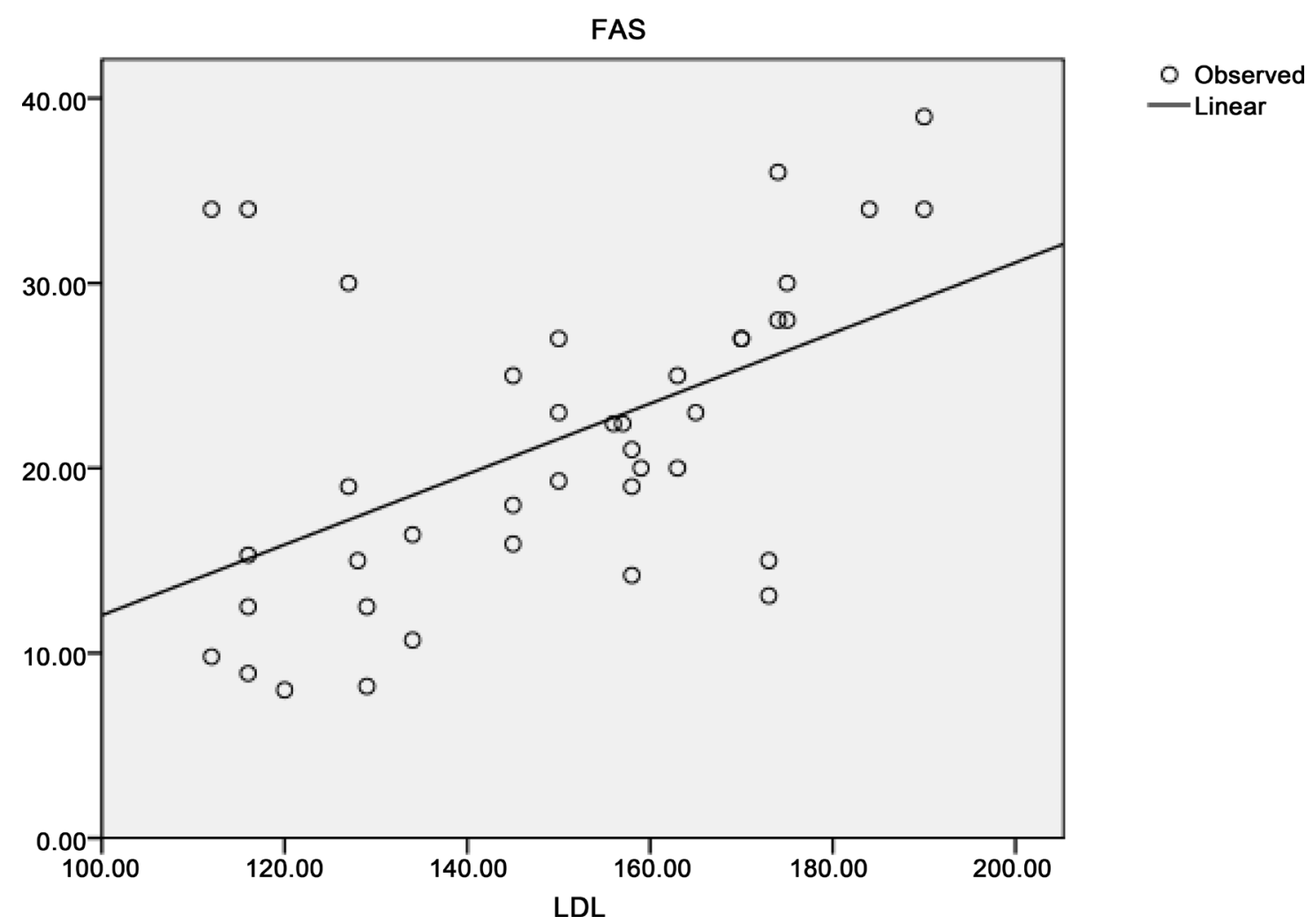

Figure 3. Linear regression analysis showing a positive correlation between LDL and FAS in NAFLD. 


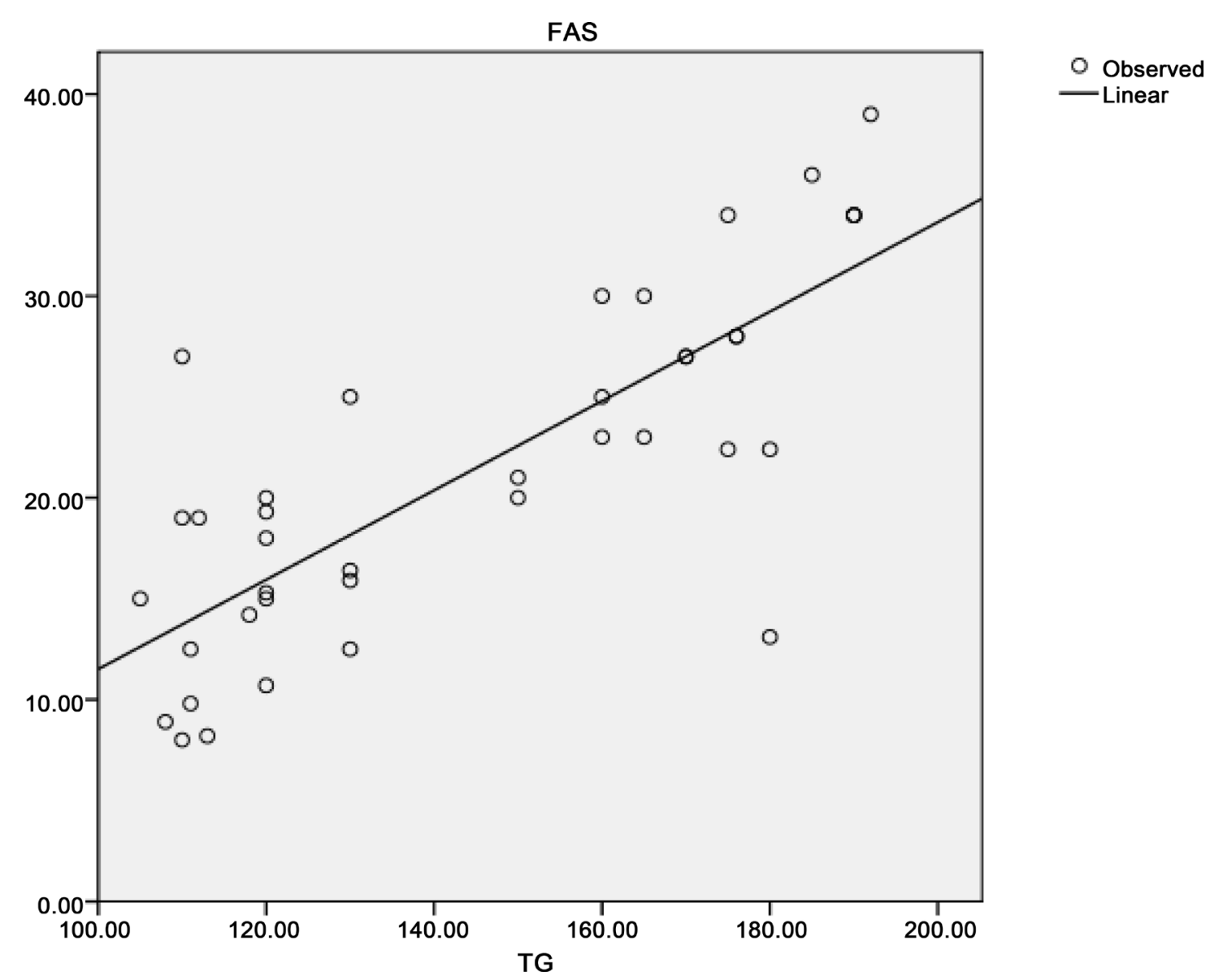

Figure 4. Linear regression analysis showing a positive correlation between TG and FAS in NAFLD.

expression in hepatocytes of NAFLD may be a compensatory adaptation which has been found in early stages of NAFLD, also over-nutrition-induced insulin resistance state and decreased de novo lipogenesis have been associated with increased FAS in serum [15] [16]. The study done by Joven et al. demonstrates increased serum levels of FAS in patients with chronic viral hepatitis and it was correlated with the degree of liver steatosis [13].

The liver the major organ for lipid metabolism, synthesis, storing, and exporting of lipids after importing the free fatty acids take place in the liver; any disturbance of these processes can lead to the fatty changes and development of NAFLD [17]. Many important cellular events depend on fatty acids such as synthesis of cellular membranes, storage of energy, and intracellular signaling pathways. However, when free fatty acids (FFAs) are chronically elevated many metabolic pathways will be disrupted and insulin resistance (IR) is induced in many organs. Hepatic fatty changes have been widely linked to IR [18] [19]. Development of IR in the peripheral adipose tissue increase the rate of lipolysis and enhance the delivery of FFAs derived from the adipose tissue to the liver. Also the presence of obesity increases the production of tumor necrosis factor $\alpha$ (TNF $\alpha$ ) in adipocytes, leading to adipocyte IR, and enhance the rate of lipolysis [20]. Thus, in obese persons the circulating FFAs is increased and is responsible for the ma- 
jority of liver lipids in NAFLD [21].

Under physiological conditions, excess of FFAs disposed by TG synthesis. The TG can then be stored within the hepatocytes or secreted into the blood as very-low-density lipoprotein (VLDL) [22]. TG synthesis seems to be an adaptive, beneficial response in situations where hepatocytes are exposed to potentially toxic TG metabolites. FFAs and cholesterol considered as aggressive lipids, as there accumulation in the mitochondria leading to liver damage mediated by TNF $\alpha$ - and then formation of reactive oxygen species (ROS). These lipids act as early "inflammatory" hits, responsible for NAFLD pathologies. Abundant FFAs cause lipotoxicity via the induction of ROS release, which causes inflammation, apoptosis, and thus, the progression to NASH and fibrogenesis [23].

\section{Conclusion}

In conclusion, FAS levels can be taken as a marker of NAFLD and hepatic steatosis.

\section{Acknowledgements}

The authors are grateful to all who participated in the study.

\section{Funding}

All needed investigations were held in Sohag university hospital, with no any external funding corporatin.

\section{Ethical Approval}

The study protocol was approved by the local ethics committee of scientific research in Sohag University, Faculty of Medicine and all patients gave their consent prior to the study.

\section{Disclosure Statement}

All authors declare that there are no financial or other conflicts of interest.

\section{References}

[1] Schwenger, K. and Allard, J.P. (2014) Clinical Approaches to Non-Alcoholic Fatty Liver Disease. World Journal of Gastroenterology, 20, 1712-1723.

http://dx.doi.org/10.3748/wjg.v20.i7.1712

[2] Calamita, G. and Portincasa, P. (2007) Present and Future Therapeutic Strategies in NonAlcoholic Fatty Liver Disease. Expert Opinion on Therapeutic Targets, 11, 1231-1249. http://dx.doi.org/10.1517/14728222.11.9.1231

[3] Jensen, M.D. (2008) Role of Body Fat Distribution and the Metabolic Complications of Obesity. The Journal of Clinical Endocrinology \& Metabolism, 93, s57-s63. http://dx.doi.org/10.1210/jc.2008-1585

[4] Jenke-Kodama, H., Sandmann, A., Müller, R. and Dittmann, E. (2005) Evolutionary Implications of Bacterial Polyketide Synthases. Molecular Biology and Evolution, 22, 2027-2039. http://dx.doi.org/10.1093/molbev/msi193 
[5] Smith, S., Witkowski, A. and Joshi, A.K. (2003) Structural and Functional Organization of the Animal Fatty Acid Synthase. Progress in Lipid Research, 42, 289-317.

http://dx.doi.org/10.1016/S0163-7827(02)00067-X

[6] Dorn, C., Riener, M.-O., Kirovski, G., Saugspier, M., Steib, K., Weiss, T.S., Gäbele, E., Kristiansen, G., Hartmann, A. and Hellerbrand, C. (2010) Expression of Fatty Acid Synthase in Nonalcoholic Fatty Liver. International Journal of Clinical and Experimental Pathology, 3, 505-514.

[7] Menendez, J.A. and Lupu, R. (2007) Fatty Acid Synthase and the Lipogenic Phenotype in Cancer Pathogenesis. Nature Reviews Cancer, 7, 763-777. http://dx.doi.org/10.1038/nrc2222

[8] Semenkovich, C.F. (1997) Regulation of Fatty Acid Synthase (FAS). Progress in Lipid Research, 36, 43-53. http://dx.doi.org/10.1016/S0163-7827(97)00003-9

[9] Oliveras-Ferraros, C., Vazquez-Martin, A., Fernández-Real, J.M. and Menendez, J.A. (2009) AMPK-Sensed Cellular Energy State Regulates the Release of Extracellular Fatty Acid Synthase. Biochemical and Biophysical Research Communications, 378, 488-493. http://dx.doi.org/10.1016/j.bbrc.2008.11.067

[10] Wang, Y.Y., Kuhajda, F.P., Li, J.N., Pizer, E.S., Han, W.F., Sokoll, L.J. and Chan, D.W. (2001) Fatty Acid Synthase (FAS) Expression in Human Breast Cancer Cell Culture Supernatants and in Breast Cancer Patients. Cancer Letters, 167, 99-104.

http://dx.doi.org/10.1016/S0304-3835(01)00464-5

[11] Vazquez-Martin, A., Fernandez-Real, J.M., Oliveras-Ferraros, C., Navarrete, J.M., MartinCastillo, B., Del Barco, S., Brunet, J. and Menendez, J.A. (2009) Fatty Acid Synthase Activity Regulates HER2 Extracellular Domain Shedding into the Circulation of HER2-Positive Metastatic Breast Cancer Patients. International Journal of Oncology, 35, 1369.

[12] Notarnicola, M., Tutino, V., Calvani, M., Lorusso, D., Guerra, V. and Caruso, M.G. (2012) Serum Levels of Fatty Acid Synthase in Colorectal Cancer Patients Are Associated with Tumor Stage. Journal of Gastrointestinal Cancer, 43, 508-511. http://dx.doi.org/10.1007/s12029-011-9300-2

[13] Joven, J., Espinel, E., Rull, A., Beltrán-Debón, R., Aragonès, G., Rodríguez-Gallego, E., Camps, J., Pedro-Botet, J., Sans, T. and Menéndez, J.A. (2011) Serum Fatty Acid Synthase Concentration Is Increased in Patients with Hepatitis Viral Infection and May Assist in the Prediction of Liver Steatosis. Journal of Clinical Virology, 51, 199-201. http://dx.doi.org/10.1016/j.jcv.2011.04.003

[14] Hsiao, P.-J., Chen, Z.-C., Hung, W.-W., Yang, Y.-H.C., Lee, M.-Y., Huang, J.-F. and Kuo, K.-K. (2013) Risk Interaction of Obesity, Insulin Resistance and Hormone-Sensitive Lipase Promoter Polymorphisms (LIPE-60 C > G) in the Development of Fatty Liver. BMC Medical Genetics, 14, 1. http://dx.doi.org/10.1186/1471-2350-14-54

[15] Fernandez-Real, J.M., Menendez, J.A., Moreno-Navarrete, J.M., Blüher, M., VazquezMartin, A., Vázquez, M.J., Ortega, F., Diéguez, C., Frühbeck, G. and Ricart, W. (2010) Extracellular Fatty Acid Synthase: A Possible Surrogate Biomarker of Insulin Resistance. Diabetes, 59, 1506-1511. http://dx.doi.org/10.2337/db09-1756

[16] Menendez, J.A., Colomer, R. and Lupu, R. (2005) Obesity, Fatty Acid Synthase, and Cancer: Serendipity or Forgotten Causal Linkage? Molecular Genetics and Metabolism, 84, 293-295. http://dx.doi.org/10.1016/j.ymgme.2004.10.007

[17] Musso, G., Gambino, R. and Cassader, M. (2009) Recent Insights into Hepatic Lipid Metabolism in Non-Alcoholic Fatty Liver Disease (NAFLD). Progress in Lipid Research, 48, 126. http://dx.doi.org/10.1016/j.plipres.2008.08.001 
[18] Petta, S., Muratore, C. and Craxi, A. (2009) Non-Alcoholic Fatty Liver Disease Pathogenesis: The Present and the Future. Digestive and Liver Disease, 41, 615-625.

http://dx.doi.org/10.1016/j.dld.2009.01.004

[19] Utzschneider, K.M. and Kahn, S.E. (2006) The Role of Insulin Resistance in Nonalcoholic Fatty Liver Disease. The Journal of Clinical Endocrinology \& Metabolism, 91, 4753-4761. http://dx.doi.org/10.1210/jc.2006-0587

[20] Hotamisligil, G.S. (2006) Inflammation and Metabolic Disorders. Nature, 444, 860-867. http://dx.doi.org/10.1038/nature05485

[21] Savage, D.B. and Semple, R.K. (2010) Recent Insights into Fatty Liver, Metabolic Dyslipidaemia and Their Links to Insulin Resistance. Current Opinion in Lipidology, 21, 329-336. http://dx.doi.org/10.1097/MOL.0b013e32833b7782

[22] Postic, C. and Girard, J. (2008) Contribution of de Novo Fatty Acid Synthesis to Hepatic Steatosis and Insulin Resistance: Lessons from Genetically Engineered Mice. The Journal of Clinical Investigation, 118, 829-838. http://dx.doi.org/10.1172/JCI34275

[23] Berlanga, A., Guiu-Jurado, E., Porras, J.A. and Auguet, T. (2014) Molecular Pathways in Non-Alcoholic Fatty Liver Disease. Clinical and Experimental Gastroenterology, 7, 221239.

\section{Submit or recommend next manuscript to SCIRP and we will provide best service} for you:

Accepting pre-submission inquiries through Email, Facebook, LinkedIn, Twitter, etc. A wide selection of journals (inclusive of 9 subjects, more than 200 journals)

Providing 24-hour high-quality service

User-friendly online submission system

Fair and swift peer-review system

Efficient typesetting and proofreading procedure

Display of the result of downloads and visits, as well as the number of cited articles Maximum dissemination of your research work

Submit your manuscript at: http://papersubmission.scirp.org/ 